\title{
Superovulation of immature hypothyroid $r d w$ rats by thyroxine therapy and the development of eggs after in vitro fertilization
}

\author{
J. Y. Jiang, K. Miyoshi, M. Umezu and E. Sato \\ Animal Reproduction Unit, Graduate School of Agriculture, Tohoku University, Sendai 981-8555, Japan
}

\begin{abstract}
The aim of this study was to examine the effect of thyroxine on ovulation in immature $r d w$ rats and the fertilization and development of the eggs. Serum thyroxine concentrations at 30 days of age were significantly lower in $r d w$ rats than in normal rats $(P<0.001)$, and greatly increased after thyroxine replacement therapy $(P<0.001)$. Although few eggs (1-5 $\pm 1-2)$ were obtained from immature $r d w$ rats treated with gonadotrophins alone, females treated with gonadotrophins and thyroxine ovulated significantly more eggs $(85 \pm 5)$. As a control, normal littermates ovulated $21-45$ eggs when treated with gonadotrophins alone, and $68 \mathrm{eggs}$ when administered with gonadotrophins and thyroxine. Of the eggs collected from $r d w$ rats treated with gonadotrophins and thyroxine, and inseminated with spermatozoa from mature $\mathrm{F}_{1}$ males, $98 \%$ were penetrated and in almost all (99\%) of these eggs, male and female pronuclei formed. Forty-seven per cent of the pronuclear eggs developed to the blastocyst stage in vitro. After transfer to recipients, $21 \%(14 / 66)$ of one-cell and $22 \%(8 / 37)$ of two-cell embryos developed to offspring, and $62 \%(8 / 13)$ of pups were of $r d w / r d w$ genotype. The average body weight (6.9 versus $7.8 \mathrm{~g}$ ) of offspring derived from one-cell embryos was lower than that for two-cell embryos. The morulae and blastocysts did not develop to term, although $41 \%$ implanted in the uterine horns of recipients. In conclusion, in immature $r d w$ rats, superovulation was induced by gonadotrophins combined with thyroxine therapy and the superovulated oocytes were fertilized and developed in vitro and developed to term after embryo transfer.
\end{abstract}

\section{Introduction}

The $r d w$ rat, a new hereditary dwarf animal, was discovered by Koto et al. (1988) in Chugai Pharmaceutical Co. Ltd, Tokyo. It was derived from an inbred colony of Wistar-Imamichi rats. The mutant was an autosomal recessive trait with infertility in both sexes, so it has been maintained by $F_{1} \times F_{1}$ mating. The $r d w$ rat is characterized by hypoplasia of the pars distalis (anterior pituitary), in particular the cells that secrete growth hormone and prolactin. This results in defects in several hormones, such as growth hormone, prolactin and thyroid hormones, but causes significantly high serum thyroid-stimulating hormone concentrations (Koto et al., 1988; Umezu et al., 1991, $1993,1995,1996)$. The $r d w$ rat is useful in endocrinological research as an animal model of human pituitary dwarfism (Koto et al., 1988) and may be an ideal model for studying the role of the thyroid in reproduction in hypothyroid animals, including humans (Cooke and Arambepola, 1997). Fertility in adult male $r d w$ rats was partly restored by thyroxine therapy (Umezu et al., 1997). Few adult female $r d w$ rats

Revised version received 9 November 1998 produced offspring when given thyroxine therapy for 1 month, and in those that did, litter sizes were small, nursing capacity was poor, and most of the pups died in the first few days after delivery. In immature female $r d w$ rats, no induction of ovulation was achieved with standard gonadotrophin treatment procedures (Jiang et al., 1996a).

Hypothyroidism results in impaired fertility in many animals (Werner, 1969), and subclinical hypothyroidism often causes infertility in humans (Mochizuki, 1977; Louvet et al., 1979; Bohnet et al., 1981; Maruo et al., 1992). These reproductive abnormalities can be improved by thyroid hormone therapy. Hagino (1971) reported that in thyroidectomized rats, ovulation was erratic, occurred in a small percentage of animals and a small number of ova were produced. These animals showed normal ovulation after Lthyroxine administration. In women, successful clinical use of thyroid hormone in the induction of ovulation in patients with subclinical hypothyroxinaemia implied that concomitant Clomiphene treatment with thyroid hormone replacement therapy is of great value for ovulation induction in patients with subclinical hypothyroxinaemia (Maruo et al., 1992).

The aim of the present study was to induce superovulation in immature $r d w$ rats and to produce $r d w$ rats by in vitro fertilization, in vitro culture and embryo transfer. 


\section{Materials and Methods}

\section{Preparation of animals}

$r d w$ rats and normal littermates (Wistar-Imamichi) were produced in the Laboratory of Animal Reproduction, Tohoku University by mating adult $F_{1}$ males with $F_{1}$ females, the offspring of which were known to include $r d w$ pups,. In this study, the term $r d w$ always refers to $r d w / r d w$ homozygotes, whereas the term normal littermates includes $\mathrm{F}_{1}(r d w /+)$ and wild-types $(+/+)$, since there are no phenotypical differences between these animals. Animals were placed in polycarbon cages $(25 \mathrm{~cm} \times 40 \mathrm{~cm} \times 20 \mathrm{~cm})$ with wood shavings on the floor, in a temperature controlled room at $24 \pm 2^{\circ} \mathrm{C}, 65 \pm 5 \%$ humidity and lights on at 5:00 $\mathrm{h}$ and off at 19:00 h. The animals were given bullet type commercial rat feed (High Pure Ace (P); Itochu Co., Ishinomaki) and tap water ad libitum. $r d w$ rats were distinguished by low body weight and retarded development of the ears, as well as a small body size at about 2 weeks of age.

\section{Hormone administration}

Immature $r d w$ rats and their normal littermates $(n=5$ in each group) were randomly divided and treated as follows to examine the roles of gonadotrophins and thyroxine hormone in ovulation in $r d w$ rats: (1) pregnant mares' serum gonadotrophin (PMSG) (10 iu); (2) PMSG and hCG (10 iu); (3) thyroxine and PMSG; and (4) thyroxine combined with PMSG and hCG. Animals were administered with thyroxine (L-thyroxine, Sigma Chemical Co., St Louis, MO) intraperitoneally once a day at 14:00 h at a dose of $10 \mu \mathrm{g}$ per $100 \mathrm{~g}$ body weight from day 21 to day 30 . The optimum dose of thyroxine was determined according to Jiang et al., 1996b. Thyroxine was dissolved in $2 \mathrm{~mol} \mathrm{NaOH} \mathrm{l}^{-1}$ and prepared in physiological saline solution (pH 8.3). PMSG (10 iu; Sankyo Kabu Company, Tokyo) was injected subcutaneously at $10: 00 \mathrm{~h}$ on day 28 , and $10 \mathrm{iu}$ hCG (Sankyo) was injected intraperitoneally $54 \mathrm{~h}$ later.

\section{Blood sampling and thyroxine determination}

Blood samples were collected from $r d w$ rats, $r d w$ rats administered with thyroxine and normal rats on day $30,48 \mathrm{~h}$ after PMSG injection, and serum was obtained by centrifugation at $900 \mathrm{~g}$ for $15 \mathrm{~min}$ at $4^{\circ} \mathrm{C}$. Serum was stored at $-40^{\circ} \mathrm{C}$ until assay. Serum thyroxine concentrations were determined using a solid method radioimmunoassay and were expressed as $\mathrm{ng} \mathrm{ml}^{-1}$.

\section{Egg collection}

Animals were killed by cervical dislocation $14 \mathrm{~h}$ after administration of hCG. Ovaries and oviducts were transferred into a glass dish $(60 \mathrm{~mm} \times 60 \mathrm{~mm})$ with PBS (Dulbecco's PBS; Nissui Pharmaceutical Co. Ltd, Tokyo). The adjunct fat was removed and ovary and oviduct were separated under a microscope. Oocyte-cumulus cell complexes were flushed out of the oviducts with PBS, treated with $0.1 \% \quad(\mathrm{w} / \mathrm{v})$ hyaluronidase (Sigma), and the number of oocytes was counted. Only those oocytes with an intact zona pellucida and homogeneous cytoplasm were considered normal and were included in the analysis.

\section{Medium}

The culture medium used in this study was mR1ECM (Miyoshi et al., 1994, 1995a) containing $76.7 \mathrm{mmol} \mathrm{NaCl} \mathrm{l}^{-1}$, $3.2 \mathrm{mmol} \mathrm{KCl} \mathrm{l}^{-1}, \quad 0.5 \mathrm{mmol} \mathrm{MgCl}_{2} \cdot 6 \mathrm{H}_{2} \mathrm{Ol}^{-1}, \quad 2.0 \mathrm{mmol}$

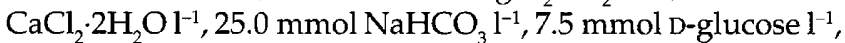
$0.5 \mathrm{mmol}^{2}$ sodium pyruvate $\mathrm{l}^{-1}$ (all from Wako Pure Chemical Industries Ltd, Osaka), $10.0 \mathrm{mmol}$ sodium lactate $\mathrm{l}^{-1}$ (Sigma), $0.1 \mathrm{mmol}$ glutamine $1^{-1}$ (Wako), $2 \%$ (v/v) minimal essential medium (MEM) essential amino acids solution $(50 \times$, No. 1000574; Gibco BRL, Grand Island, NY), 1\% (v/v) MEM nonessential amino acids solution (100×, No. 1001447; Gibco BRL), $1.0 \mathrm{mg}$ polyvinylalcohol (PVA) $\mathrm{ml}^{-1}$ (Sigma).The fertilization medium was $\mathrm{mR} 1 \mathrm{ECM}$ containing $100 \mathrm{mmol}$ $\mathrm{NaCl} \mathrm{l}^{-1}$ and $4 \mathrm{mg} \mathrm{BSA} \mathrm{ml}^{-1}$ (No. A-7638, Fraction V; Sigma) and omitting PVA (Oh et al., 1997). Fertilization and culture media ( $400 \mu \mathrm{l}$ per drop) were prepared in polystyrene culture dishes (35 mm $\times 14 \mathrm{~mm}$; Sumitomo Bakelite Co. Ltd, Tokyo), covered with paraffin oil (No. 261-17; Nacalai Tesque Inc., Kyoto) and equilibrated overnight in a $\mathrm{CO}_{2}$ incubator $(5 \%$ $\mathrm{CO}_{2}$ in air at $37^{\circ} \mathrm{C}$ ).

\section{Preparation of sperm suspension}

Spermatozoa were obtained from $\mathrm{F}_{1}$ males at about 8 months to 1 year as described by Miyoshi et al. (1997). Briefly, one drop of a dense mass of spermatozoa was introduced into pre-equilibrated insemination medium $(400 \mu 1)$. After about 5 min warming in the incubator, $10-60 \mu l$ of the sperm suspension was transferred into drops of insemination medium to give a final sperm concentration of $1 \times 10^{6}$ cells $\mathrm{ml}^{-1}$. The diluted sperm suspensions were preincubated for 5 to $7 \mathrm{~h}$ in a $\mathrm{CO}_{2}$ incubator.

\section{Collection of cumulus-oocyte complexes and in vitro fertilization}

Animals treated with thyroxine and PMSG were killed by cervical dislocation 13-14 $\mathrm{h}$ after hCG injection (Toyoda and Chang, 1974). Oviducts were isolated, placed on a piece of sterilized filter paper to remove the liquid and blood on the surface, and placed in the dishes containing the diluted sperm suspension. The cumulus-oocyte complexes in the oviducts were carefully released into the sperm suspension. The dishes were kept in $\mathrm{CO}_{2}$ incubator for $10 \mathrm{~h}$.

\section{Examination of fertilization}

Methods for examining penetration and polyspermy were as described by Toyoda and Chang (1974) and Miyoshi et al. 
(1995b, 1997). Briefly, after incubation, eggs were transferred into $100 \mu \mathrm{l}$ culture medium and freed from surrounding cumulus cells by repeated pipetting with a fine pipette. The denuded eggs were placed in the centre of four vaseline spots on a glass slide, compressed gently with a cover slip, fixed briefly with $2.5 \%(\mathrm{v} / \mathrm{v})$ glutaraldehyde in phosphate buffer solution and in $10 \%(\mathrm{v} / \mathrm{v})$ neutral formalin at room temperature for 4-6h, stained with lacmoid and examined under a phase-contrast microscope. Eggs were considered penetrated when a spermatozoon was observed inside the perivitelline space or when the eggs had pronuclei with sperm tails in the vitellus (Toyoda and Chang, 1974). Eggs containing two or more enlarged sperm heads or male pronuclei in the vitellus with corresponding tails were considered polyspermic (Miyamoto and Chang, 1973).

\section{Embryo culture in vitro}

Embryo culture and examination of development were conducted as described by Miyoshi et al. (1995b). Briefly, $10 \mathrm{~h}$ after insemination, eggs were separated from cumulus cells, washed three to six times with culture medium and examined under a phase-contrast microscope for evidence of fertilization. Approximately 10-20 eggs with female and male pronuclei with corresponding tails were transferred to $400 \mu \mathrm{l}$ culture medium and cultured in a $\mathrm{CO}_{2}$ incubator for 5 days.

\section{Embryo transfer}

The procedures for inducing pseudopregnancy and transfer were as described by Toyoda and Chang (1974), with the exception that two-cell embryos were transferred to day 1 (day of ovulation) rather than day 2 pseudopregnant recipients. Briefly, 4- to 5-month-old rats (200-280 g) that were in oestrus for at least three consecutive regular 4 day periods were stimulated by inserting a plastic rod connected to two electrodes $(20 \mathrm{~V})$ into the vagina and switching it on and off for 3 seconds three times on the morning of day 4 (pro-oestrus, the day before ovulation) and day 1 . Seven to ten embryos at the one- or two-cell stage were transferred to the oviducts of each recipient on day 1 . After 4-5 days of culture in vitro, morulae or blastocysts were transferred to the uterine horns of recipient rats whose oestrous cycles were 1 day later (day 2) than those receiving one- or two-cell embryos. All transferred embryos were derived from eggs of immature $r d w(r d w / r d w)$ rats fertilized in vitro with epididymal spermatozoa of mature $\mathrm{F}_{1}(r d w /+)$ males. Recipients were checked once a day by smear examination. Recipients that showed pro-oestrous or oestrous smears, or were pregnant but did not deliver offspring by day 24 of pregnancy, were killed and their uterine horns were examined for implantation sites. The number of young born was counted on the day of parturition. The young were weighed on the day of birth. $r d w$ rats were identified as described earlier.

\section{Statistical analysis}

Serum thyroxine concentrations and data for egg counts (Table 1) were expressed as mean \pm SEM and assigned for oneway or three-way analysis of variance (ANOVA), respectively. When ANOVA revealed a significant treatment effect, the treatments were compared by Duncan's new multiple-range test. The weight of newborns (Table 2) was analysed by paired Student's $t$ test.

\section{Results}

Serum thyroxine concentrations at 30 days of age were significantly lower in $r d w$ rats $\left(13.6 \pm 1.1 \mathrm{ng} \mathrm{ml}^{-1}\right)$ than in normal rats $\left(32.8 \pm 0.7 \mathrm{ng} \mathrm{ml}^{-1}, \quad P<0.001\right)$, and were significantly higher $\left(58.5 \pm 3.0 \mathrm{ng} \mathrm{ml}^{-1}, \quad P<0.001\right)$ after thyroxine replacement therapy from day 21 to day 29 .

hCG increased the ovulation rate in both $r d w$ rats and normal littermates (Table 1). When PMSG was administered alone or with thyroxine, ovulation rates were 40 and $20 \%$ in $r d w$ rats and 40 and $60 \%$ in normal rats, respectively, and increased to $100 \%$ in both groups when hCG was administered in the presence of PMSG alone or with thyroxine. hCG also increased the egg counts in normal rats (45 versus 21 ) but not in $r d w$ rats (5 versus 3 ) pre-stimulated with PMSG. However, no additive effect was observed with thyroxine in the presence of PMSG. The combined treatment

Table 1. Effect of gonadotrophins and thyroxine on ovulation in immature $r d w$ rats and normal littermates

\begin{tabular}{|c|c|c|c|c|c|c|}
\hline \multicolumn{3}{|c|}{ Hormones administered } & \multicolumn{2}{|c|}{$r d w$} & \multicolumn{2}{|c|}{ Normal } \\
\hline Thyroxine & PMSG & hCG & $\begin{array}{c}\text { Number of rats } \\
\text { ovulating }\end{array}$ & $\begin{array}{l}\text { Number of eggs } \\
\text { collected per rat }\end{array}$ & $\begin{array}{c}\text { Number of rats } \\
\text { ovulating }\end{array}$ & $\begin{array}{l}\text { Number of eggs } \\
\text { collected per rat }\end{array}$ \\
\hline _- & + & - & $2 / 5$ & $3 \pm 2^{a}$ & $2 / 5$ & $21 \pm 13$ \\
\hline - & + & + & $5 / 5$ & $5 \pm 2^{a *}$ & $5 / 5$ & $45 \pm 12$ \\
\hline+ & + & - & $1 / 5$ & $1 \pm 1^{\mathrm{a}}$ & $3 / 5$ & $26 \pm 15$ \\
\hline+ & + & + & $5 / 5$ & $85 \pm 5^{b}$ & $5 / 5$ & $68 \pm 12$ \\
\hline
\end{tabular}

abValues with different superscripts within each column are significantly different $(P<0.01)$.

${ }^{*}$ The number of eggs collected in $r d w$ rats is significantly lower than in normal littermates given the same treatment $(P<0.05)$.

PMSG, pregnant mares' serum gonadotrophin. 
Table 2. Pregnancies and offspring derived from oocytes of $r d w / r d w$ rats fertilized in vitro with epididymal spermatozoa from $r d w /+$ males and transferred to pseudopregnant recipients

\begin{tabular}{|c|c|c|c|c|c|c|c|c|}
\hline \multirow[b]{2}{*}{$\begin{array}{l}\text { Stage of embryos } \\
\text { transferred }\end{array}$} & \multirow[b]{2}{*}{$\begin{array}{l}\text { Number }(\%) \text { of } \\
\text { pregnancies }\end{array}$} & \multirow[b]{2}{*}{$\begin{array}{c}\text { Number }(\%) \text { of } \\
\text { litters }\end{array}$} & \multirow[b]{2}{*}{$\begin{array}{c}\text { Number of embryos } \\
\text { transferred }\end{array}$} & \multicolumn{4}{|c|}{ Number of offspring } & \multirow[b]{2}{*}{$\begin{array}{c}\text { Average weight (range) } \\
\text { of newborns }(\mathrm{g})\end{array}$} \\
\hline & & & & $\begin{array}{l}\text { Total } \\
(\%)^{*}\end{array}$ & $\begin{array}{l}\text { Male } \\
(r d w)\end{array}$ & $\begin{array}{l}\text { Female } \\
\quad(r d w)\end{array}$ & Dead $^{+}$ & \\
\hline One-cell & $7 / 7(100)$ & $5 / 7(71)$ & 66 & $14(21)$ & $7(4)$ & $6(4)$ & 1 & $6.9(5.9-8.2)^{\mathrm{a}}$ \\
\hline Two-cell & $5 / 5(100)$ & $4 / 5(80)$ & 37 & $8(22)$ & nt & nt & 8 & $7.8(6.9-9.4)^{\mathrm{b}}$ \\
\hline Morulae and blastocysts & $10 / 10(100)$ & $0 / 10(0)$ & 85 & $0(0)$ & - & - & - & - \\
\hline
\end{tabular}

"Values with different superscripts within each column are significantly different $(P<0.01)$.

* Percentage of the embryos transferred.

'Died within 2 weeks after birth.

nt, not tested.

of PMSG and hCG with thyroxine therapy significantly increased the number of ovulated eggs in both $r d w$ rats $(85$, $P<0.001$, low variation) and normal littermates $(68, P<0.05$, high variation) compared with other treatments.

In the in vitro fertilization experiment, $89(97.8 \%)$ of 91 inseminated eggs were penetrated in vitro and most $(98.9 \%)$ had pronuclei. A small percentage (3.4\%) of fertilized eggs were polyspermic; $2.2 \%$ of eggs showed fragmentation $10 \mathrm{~h}$ after insemination.

In the eggs fertilized in vitro, $100 \%(45 / 45), 78 \%(35 / 45)$, $69 \%(31 / 45)$ and $47 \%(21 / 45)$ developed in vitro to two-cell, beyond four-cell, morula and blastocyst stages, respectively. After transfer to the recipients, $21 \%$ of one-cell and $22 \%$ of two-cell embryos developed to offspring. However, none of the morulae or blastocysts developed to term. Four male and four female pups were determined to be $r d w$ rats. The average body weight for newborns derived from two-cell embryos $(7.8 \mathrm{~g})$ was significantly greater than those from one-cell embryos (6.9 g) (Table 2).

\section{Discussion}

Numerous studies have examined the effects of hypothyroidism on reproduction in female animals. However, most of these have used thyroidectomy (Hagino 1971; Peppler et al., 1975; Ruiz et al., 1989; Mattheij et al., 1995) or chemical induction (Baksi, 1973; Lee et al., 1991; Bagavandoss et al., 1998). The congenital hypothyroid $r d w$ rat parallels more closely the human clinical syndrome, as increased testicular size in hypothyroid boys may be more useful as a model for the human condition than propylthiouracil-treated rats (Cooke and Arambepola, 1997). In hypothyroid women with weight loss amenorrhoea, no ovulation was induced by Clomiphene therapy, but ovulation increased markedly after combined treatment with thyroid hormone replacement and Clomiphene citrate (Maruo et al., 1992). In rdw rats, superovulation was not induced by gonadotrophins alone, but was induced by a combined treatment of thyroxine replacement therapy and gonadotrophin administration. These similarities imply that female $r d w$ rats are a useful model for the condition in women.

Thyroid hormone deficiency can cause a number of disorders in reproduction such as disruption of ovulation, sterility and abortion (Werner, 1969). In hypothyroid animals, these abnormalities can be partially or completely reversed by thyroxine replacement therapy. Reproduction and lactation in dwarf female mutant $d w$ and $d f$ mice can be induced with a diet supplemented with desiccated thyroid powder (Bartke, 1965a,b). Hypothyroid mice respond to thyroid hormone therapy with improved growth and fertility (Beamer et al., 1981). In women, the induction rate of ovulation with Clomiphene citrate in patients with weight loss amenorrhoea increased as serum triiodothyronine concentrations increased from 80 to $140 \mathrm{ng} \mathrm{dl}^{-1}$ (Maruo et al., 1992). Hagino (1971) reported that in thyroidectomized rats, both vaginal cornification and ovulation (with a small number of ova) were delayed. When PMSG was administered at 28 days of age, ovulation was erratic, occurred in a small percentage of animals and a small number of ova were produced on both day 30 and day 31 . However, thyroxine admininstration with PMSG injection allowed normal ovulation on day 31 (14 ova per animal). The results of the present study also show that thyroxine replacement therapy combined with gonadotrophin administration plays an important role in inducing ovulation in $r d w$ rats. However, there were large differences in the number of oocytes in these two studies, which may be due to the different states of hypothyroidism and different doses of thyroxine in the replacement therapy. The tendency of $r d w$ rats to have low body weights at birth indicates that spontaneous hypothyroidism began at birth or earlier, whereas in thyroidectomized rats, hypothyroidism did not commence before 24 days of age at which time the thyroid gland was removed. In addition, $r d w$ rats were given $10 \mu \mathrm{g}$ thyroxine per $100 \mathrm{~g}$ body weight once a day, whereas $3.5 \mu \mathrm{g}$ per $60 \mathrm{~g}$ body weight (about $5.8 \mu \mathrm{g}$ per $100 \mathrm{~g}$ ) was administered to thyroidectomized rats (Hagino, 1971).

The induction of transient hypothyroidism from birth to day 25 in neonatal male rats with propylthiouracil and subsequent recovery to euthyroidism resulted in an increase in adult testis mass and daily sperm production of 80 and $140 \%$, respectively (Cooke and Arambepola, 1997). These results were attributed to the extended proliferation and greater final population of Sertoli cells (Cooke et al., 1991; van Haaster et al., 1992; Hess et al., 1993). In females, the stimulatory action of thyroid hormone on granulosa cell 
differentiation was demonstrated by in vitro and in vivo studies. Thyroid hormone plays an important role in the functional differentiation of granulosa cells. However, treatment of cultured granulosa cells with thyroid hormone alone was incapable of inducing the stimulatory effects, thus synergism between thyroid hormone and FSH seems to play a vital role in granulosa cell differentiation (Maruo et al., 1987; Maruo, 1988; Mochizuki and Maruo, 1988). In rats, prepubertal hypothyroidism induced by 6-propil-2thiouracil from birth to day 40 post partum interfered with differentiation of granulosa cells and resulted in a greater number of secondary follicles, fewer antral follicles, smaller non-atretic antral follicles, and more atretic follicles in the ovaries at day 40 compared with untreated rats (Dijkstra et al., 1996). In addition, the number of ovulations decreased, since hypothyroidism reduced the number of follicles that were able to ovulate (Mattheij et al., 1995). The evidence that thyroxine administration in the presence of PMSG increased the number of healthy large and small follicles may explain the marked results for oocytes in immature $r d w$ rats (85 eggs per animal) compared with their normal counterparts $(68$ eggs per animal). It is clear that neonatal hypothyroidism resulted in an enlarged pool of secondary follicles, and thyroxine and PMSG administration allowed granulosa cell differentiation of secondary follicles and improved cell growth. As a result, large antral follicles developed and these were triggered to ovulate by hCG, which was shown to be necessary for superovulation in this study. The mechanism by which $h \mathrm{CG}$ affects superovulation in $r d w$ rats remains to be elucidated.

In immature rats, a single injection of PMSG was effective for superovulation and egg counts of 33-34 were observed in treated Sprague-Dawley rats (Walton et al., 1983; Armstrong and Opavsky, 1988). In the present study, fewer eggs were produced in PMSG-primed normal Wistar-Imamichi rats, indicating that these animals were less sensitive to PMSG than those used in the previous studies. The protocol that combines $10 \mathrm{iuhCG}$ and $10 \mathrm{iu}$ PMSG is widely used to obtain eggs for in vitro fertilization (Miyamoto and Chang, 1973; Toyoda and Chang, 1974; Miyamoto and Ishibashi, 1975; Niwa and Chang, 1975; Vanderhyden and Armstrong, 1989). hCG treatment also enhances the ovulation in adult rats pretreated with high doses of PMSG (Welschen and Rutte, 1971; Greenwald and Terranova, 1988). In the present study, normal immature littermates administered with $10 \mathrm{iu}$ hCG ovulated 45 eggs, indicating that the superovulation was effective. In contrast, only a few eggs were obtained in immature $r d w$ rats that received the same treatment, and no improvement was observed after combined treatment with hCG, indicating that hormone therapy is necessary for normal superovulation. The fact that the combined treatment of PMSG and hCG with thyroxine therapy induced superovulation (85 eggs per rat) in $r d w$ rats similar to that in normal rats after FSH treatment (60-85 eggs per rat; Armstrong and Opavsky, 1988) supports this proposal.

Eggs produced after treatment with PMSG at appropriate concentrations developed normally with (Toyoda and Chang, 1974; Walton and Armstrong, 1983; Vanderhyden et al., 1986; Vanderhyden and Armstrong, 1989) or without transfer (Nuti et al., 1975). In the present study, the eggs derived from PMSG-primed $r d w$ rats had a high in vitro fertilization rate (97.8\%). After fertilization, $47 \%$ of one-cell embryos developed to blastocysts, which was low compared with naturally ovulated eggs fertilized in vivo or in vitro and cultured in vitro (Miyoshi et al., 1994, 1995a,b, 1997; Oh et al., 1997), indicating that eggs derived from immature $r d w$ rats have reduced developmental ability.

Miyoshi et al. (1997) reported that $25 \%$ of late fetuses or pups were produced after transfer of morulae or blastocysts to recipients. The reason why no pups were derived from morulae or blastocysts in the present study is unclear. However, 21 and $22 \%$ of one- and two-cell embryos, respectively, developed to term after transfer. This supports the findings of Toyoda and Chang (1974) that in immature rats, $21 \%$ of two-cell embryos derived from embryos fertilized in vitro developed to fetuses and newborn young. The fact that some of the offspring derived from one-cell embryos in the current study were $r d w$ rats shows that this procedure can be used to produce $r d w$ pups from infertile immature $r d w$ rats for research purposes.

In conclusion, in infertile immature $r d w$ rats, superovulation was induced by gonadotrophins with thyroxine replacement therapy. The superovulated eggs developed to blastocysts in vitro and to term after in vitro fertilization with spermatozoa from $\mathrm{F}_{1}$ males and transfer of early stage embryos. About $50 \%$ of the offspring produced in this system were $r d w$, thus the method could be useful in endocrinological research as well as for the production of $r d w$ rats.

The authors would like to thank M. Hirabayashi of the Research Institute of Life Science, Snow Brand Milk Products, Co. Ltd, for the demonstration of embryo transfer in rats. This work was supported by grants for the Program for Promotion of Basic Research Activities for Innovative Biosciences and 'Research for the Future' Program, The Japan Society for the Promotion of Science (JSPS-RFTF97L00904).

\section{References}

Armstrong DT and Opavsky MA (1988) Superovulation of immature rats by continuous infusion of follicle-stimulating hormone Biology of Reproduction 39 511-518

Bagavandoss P, England B, Asirvatham A and Bruot BC (1998) Transient induction of polycystic ovary-like syndrome in immature hypothyroid rats Proceedings of the Society for Experimental Biology and Medicine 21977-84

Baksi SN (1973) Effect of propylthiouracil-induced hypothyroidism on serum levels of luteinizing hormone and follicle-stimulating hormone in the rat Joumal of Endocrinology 59 655-656

Bartke A (1965a) Influence of luteotrophin on fertility of dwarf mice Journal of Reproduction and Fertility 1093-103

Bartke A (1965b) The response of two types of dwarf mice to growth hormone, thyrotropin, and thyroxine General and Comparative Endocrinology 5 418-426

Beamer WG, Eicher EM, Maltais LJ and Southard JL (1981) Inherited primary hypothyroidism in mice Science 212 61-63

Bohnet HG, Fiedler $K$ and Leidenberger FA (1981) Subclinical hypothyroidism and infertility Lancet ii 1278

Cooke P and Arambepola N (1997) Thyroid hormone effects on testicular growth, maturation and function. In Current Advances in Andrology pp 311-316 Eds GMH Waites, J Frick and GWH Baker. Litosei-RastignanoBologna Press, Italy

Cooke PS, Hess RA, Porcelli J and Meisami E (1991) Increased sperm production in adult rats following transient neonatal hypothyroidism Endocrinology 129 244-248

Dijkstra G, de Rooij DG, de Jong FH and van den Hurk R (1996) Effect of hypothyroidism on ovarian follicular development, granulosa cell 
proliferation and peripheral hormone levels in the prepubertal rat European Journal of Endocrinology 134 649-654

Greenwald GS and Terranova PF (1988) Follicular selection and its control. In The Physiology of Reproduction pp 387-445 Eds E Knobil and JD Neill. Raven Press, New York

Hagino N (1971) Influence of hypothyroid state on ovulation in rats Endocrinology 88 1332-1336

Hess RA, Cooke PS, Bunick D and Kirby JD (1993) Adult testicular enlargement induced by neonatal hypothyroidism is accompanied by increased Sertoli and germ cell numbers Endocrinology 132 2607-2613

Jiang JY, Umezu M, Sato H and Sugawara S (1996a) Characteristics of infertility in female $r d w$ rats especially responding to gonadotropins Proceedings of the 13th International Congress on Animal Reproduction (Sydney, Australia) 2 Abstract P4-22

Jiang JY, Umezu M and Kagabu S (1996b) L-thyroxine (T4) enhanced gonodotropin-induced ovulation in immature $r d w$ rats Proceedings of 2 nd Asian Symposium on Animal Biotechnology (Nanjing, China) pp 405-412

Koto M, Sato T, Okamoto M and Adachi J (1988) rdw rats, a new hereditary dwarf model in the rat Experimental Animal 37 21-30 (in Japanese)

Lee MT, Adams WC and Bruot BC (1991) Circulating hormone concentrations in hypothyroid rats with induced polycystic ovaries Proceedings of the Society for Experimental Biology and Medicine 198 737-741

Louvet JP, Gouarre M, Salandini AM and Boulard CL (1979) Hypothyroidism and anovulation Lancet i 1032

Maruo T (1988) The role of growth factors in the expression of differentiated functions of the ovary and placenta Folia Endocrinologica 64 1214-1222

Maruo T, Hayashi M, Matsuo H, Yamamoto T, Okada $H$ and Mochizuki M (1987) The role of thyroid hormone as a biological amplifier of the actions of follicle-stimulating hormone in the functional differentiation of cultured porcine granulosa cells Endocrinology 121 1233-1241

Maruo T, Katayama K, Barnea ER and Mochizuki M (1992) A role for thyroid hormone in the induction of ovulation and corpus luteum function Hormone Research 37 Supplement 1 12-18

Mattheij JAM, Swarts JJM, Lokerse P, van Kampen JT and Van der Heide D (1995) Effect of hypothyroidism on the pituitary-gonadal axis in the adult female rat Journal of Endocrinology 146 87-94

Miyamoto $\mathrm{H}$ and Chang MC (1973) Fertilization of rat eggs in vitro. Biology of Reproduction 9 384-393

Miyamoto H and Ishibashi T (1975) The role of calcium ions in fertilization of mouse and rat eggs in vitro. Journal of Reproduction and Fertility 45 523-526

Miyoshi K, Funahashi H, Okuda K and Niwa K (1994) Development of rat one-cell embryos in a chemically defined medium: effects of glucose, phosphate and osmolarity Journal of Reproduction and Fertility 100 21-26

Miyoshi K, Abeydeera LR, Okuda K and Niwa K (1995a) Effects of osmolarity and amino acids in a chemically defined medium on development of rat one-cell embryos Journal of Reproduction and Fertitity 103 27-32

Miyoshi K, Tanaka N and Niwa K (1995b) Penetration in vitro of naturally ovulated rat eggs and the development of eggs in a chemically defined medium Journal of Mammalian Ova Research 12 35-39

Miyoshi K, KonoT and Niwa K (1997) Stage-dependent development of rat 1-cell embryos in a chemically defined medium after fertilization in vivo and in vitro. Biology of Reproduction 56 180-185

Mochizuki M (1977) The thyroid gland and menstrual disorders Obstetrics and Gynecological Therapy 35 641-645

Mochizuki M and Maruo T (1988) Thyroid hormone synergizes with folliclestimulating hormone in the expression of differentiated functions of porcine granulosa cells. In Preservation of Tubo-Ovarian Function in Gynecologic Benign and Malignant Diseases pp 69-84 Eds K Ichinoe, SJ Segal and L Mastroianni. Raven Press, New York

Niwa K and Chang MC (1975) Fertilization of rat eggs in vitro at various times before and after ovulation with special reference to fertilization of ovarian oocytes matured in culture Journal of Reproduction and Fertility 43 435-451

Nuti KM, Sridharan BN and Meyer RK (1975) Reproductive biology of PMSG-primed immature female rats Biology of Reproduction 13 38-44

Oh SH, Funahashi $\mathbf{H}$ and Niwa $\mathrm{K}$ (1997) Effect of $\mathrm{NaCl}$ concentration in fertilization medium on sperm penetration and early development of rat eggs Journal of Mammalian Ova Research 14 S17 (abstract in Japanese)

Peppler RD, Hess M and Dunn JD (1975) Compensatory ovulation after unilateral ovariectomy in thyroidectomized rats journal of Endocrinology 66 137-138

Ruiz M, Diego AM, Reyes A, Alonso A and Morell M (1989) Influence of thyroidectomy on serum and pituitary FSH in control and orchidectomized rats Research Experimental Medicine 189 85-90

Toyoda $Y$ and Chang MC (1974) Fertilization of rat eggs in vitro by epididymal spermatozoa and the development of eggs following transfer Journal of Reproduction and Fertility 369-22

Umezu M, Kawada K, Ishii-Miwa A, Ishii S and Masaki J (1991) Pituitary and plasma levels of growth hormone (GH), follicle-stimulating hormone (FSH) and luteinizing hormone (LH) in hereditary dwarf rats ( $r d w / r d w)$ Experimental Animal 40 511-515

Umezu M, Fujimura T, Sugawara S and Kagabu S (1993) Pituitary and serum levels of prolactin (PRL), thyroid stimulating hormone (TSH) and serum thyroxine (T4) in hereditary dwarf rats $(r d w / r d w)$ Experimental Animal $\mathbf{4 2}$ 211-216

Umezu M, Kagabu S, Ishii S, Furusawa T, Ishii-Miwa A, Oohashi S and Sugawara S (1995) Endocrinological analysis in model animals with genetic defects $-r d w$ rats, a new hereditary dwarf model in the rat Proceedings of $1 s t$ East Asian Symposium on Animal Biotechnology (Sendai, Japan) 1 161-167

Umezu M, Kagabu S, Ishii-Miwa A, Ishii S, Jiang JY, Sato $H$ and Sugawara S (1996) Endocrinological characteristics in animals with genetic defects $-r d w$ rats, a hereditary dwarf with large testis in advanced age Proceedings of 13th International Congress on Animal Reproduction (Sydney, Australia) 3 Abstract 26-8

Umezu M, Kagabu S and Jiang JY (1997) Recovery of impaired testis function in hereditary hypothyroidism aged $r d w$ rats with thyroxine (T4) therapy Journal of Andrology 20 Supplement 173

van Haaster LH, de Jong FH, Docter R and de Rooij DG (1992) The effect of hypothyroidism on Sertoli cell proliferation and differentiation and hormone levels during testicular development in the rat Endocrinology 131 1574-1576

Vanderhyden BC and Armstrong DT (1989) Role of cumulus cells and serum on the in vitro maturation, fertilization, and subsequent development of rat oocytes Biology of Reproduction 40 720-728

Vanderhyden BC, Rouleau A, Walton EA and Armstrong DT (1986) Increased mortality during early embryonic development after in vitro fertilization of rat oocytes Journal of Reproduction and Fertility 77 401-409

Walton EA and Armstrong DT (1983) Oocyte normality after superovulation in immature rats Journal of Reproduction and Fertility 67 309-314

Walton EA, Evans G and Armstrong DT (1983) Ovulation response and fertilization failure in immature rats induced to superovulate journal of Reproduction and Fertility 67 91-96

Welschen R and Rutte $\mathbf{M}$ (1971) Ovulation in adult rats after treatment with pregnant mare serum gonadotrophin during oestrus Acta Endocrinologica 68 41-49

Werner SC (1969) Reproductive system. In The Thyroid - A Fundamental and Clinical Text pp 656-665 Ed. SC Werner. Hakko Company Ltd, Tokyo 